\title{
The Shewhart attribute chart with alternated charting statistics to monitor bivariate and trivariate mean vectors
}

\author{
Roberto Campos Leoni ${ }^{\mathrm{a}, 1, *}$, Antonio Fernando Branco Costa ${ }^{\mathrm{b}, 2}$ \\ a Department of Statistics at Agulhas Negras Military Academy (AMAN), Resende, RJ, Brazil \\ b Production Department, São Paulo State University (UNESP), Guaratinguetá, SP, Brazil
}

\section{A R T I C L E I N F O}

\section{Keywords:}

ACS mpchart

Alternated charting statistic

Bivariate processes

Trivariate processes

Shewhart attribute chart

\begin{abstract}
A B S T R A C T
In this article, we combined the Alternated Charting Statistic (ACS) scheme with the traditional attribute $n p$ chart to control mean vectors of bivariate and trivariate normal processes. With the bivariate ACS scheme in use (the trivariate scheme is similar), the two quality characteristics $(X, Y)$ are controlled in an alternating fashion. If the current sample point is the number of disapproved items with respect to the $X$ discriminating limits, then the next sample point will be the number of disapproved items with respect to the $Y$ discriminating limits. The strategy of using the $X$ discriminating limits to classify the items of one sample and the $Y$ discriminating limits to classify the items of the next sample instead of using jointly the $X$ and $Y$ discriminating limits to classify the items of all samples might be compensated with the adoption of larger samples. In other words, the proposed bivariate (trivariate) ACS chart might work with samples as large as $2 n(3 n) ; n$ is the sample size of the competing Hotelling and Max $D$ charts. The proposed chart resembles an $n p$ chart with alternated charting statistic; because of that, it is called the ACS $m p$ chart. The ACS $m p$ chart always outperforms the Max D chart and, in comparison with the standard $T^{2}$ chart and with the combined Max $D-T^{2}$ chart, it has a better overall performance. With the ACS scheme, the items are classified as approved or disapproved regarding only one of the two quality characteristic, $X$ or $Y$; with the Max $D$ chart the complexity increases, once the items are classified into four different categories: approved (disapproved) regarding both, the $X$ and $Y$ discriminating limits, or approved (disapproved) regarding the $X$ discriminate limits and disapproved (approved) regarding the $Y$ discriminate limits. The $T^{2}$ chart always requires the measurement of the two quality characteristics. The additional advantage of inspecting only one quality characteristic of the sample items lies in the fact that the $X Y$-correlation doesn't need to be estimated.
\end{abstract}

\section{Introduction}

Control charts are monitoring tools specially designed to detect assignable causes. The $\bar{X}$ and the $T^{2}$ charts are the standard tools to control the mean and the mean vector, however, in some applications, the expensive and time-consuming measurements might be avoided with the use of attribute charts. The attribute charts work with the number of nonconforming sample items; the construction of inspecting devices such as "go/ no-go" gauges allow, with minimum effort, to classify the sample items as conforming or nonconforming. The study of attribute charts and the charts with attribute and variable inspecting stages, specially designed to control the process parameters (mean, mean vector, variance, and covariance matrix) is growing fast.

$\mathrm{Wu}$ and Jiao (2008) introduced the idea of monitoring the process mean without measuring the $X$ quality characteristic. Following the work of Wu and Jiao (2008), Wu, Khoo, Shu, and Jiang (2009) proposed a new type of $n p$ control chart to control the process mean. The distinctive feature of their chart is the way the sample items are classified; the usual defective/non-defective classification is replaced by the conforming/nonconforming one. A nonconforming item is not necessarily defective. Ho and Costa (2011) proposed an $n p$ chart to control a wandering mean. The mean wanders around its target position, even in the absence of assignable causes. After the assignable cause occurrence, it starts wandering around an off-target position. Ho and Quinino (2013) used an attribute chart to control the process variability. Their $n p$ chart offers an economic advantage over the variance chart when the cost of classifying the sample items as approved or disapproved is approximately $25 \%$ lower, on average than the cost of measuring the

\footnotetext{
* Corresponding author.

E-mail address: leoni.roberto@aman.eb.mil.br (R.C. Leoni).

${ }^{1}$ His current research interest is in statistical quality control and multivariate statistics.

${ }^{2}$ He has received a Best Paper Award from IIE Transactions. His current research interest is in statistical quality control and design of experiments.
} 
sample items. Sampaio, Ho, and de Medeiros (2014) proposed a double sampling scheme to control the process mean; the sample is split into two subsamples, the first one is inspected by attribute and, depending on the number of disapproved items in this first subsample, the items of the second subsample are inspected by variable. The Sampaio's chart exhibits good performance in signaling mean shifts lower than one standard deviation. Haridy, Wu, Lee, and Rahim (2014) considered an attribute inspection for monitoring both, the process mean and the process variance. Aslam, Azam, Khan, and Jun (2015) and Aslam, Khan, Aldosari, and Jun (2016) proposed the mixed control chart, where the sample items are classified as defective or not defective and, depending on the number of defectives, the quality characteristic $X$ of the sample items are also measured. Quinino, Ho, and Trindade (2015) proposed an attribute chart to control the process mean where each sample item is classified as type 1, if its value is lower than the lower warning limit ( $L W L$ ), type 2 if its value is higher than the upper warning limit (UCL), and type 3 , if its value is higher than the $L W L$ and lower than the UCL.

Ho and Quinino (2016) also considered a double sampling scheme to control the process variability. The sample is split into two subsamples; the first one is inspected by attribute and, depending on the length of items sequentially classified as approved or disapproved, the items of the second subsample are inspected by variable and its variance is used to decide the state of the process (in control or out of control). Ho and Aparisi (2016) introduced the idea of monitoring the process mean with the conventional $n p$ and $\bar{X}$ charts. If the disapproved items in the sample exceed a threshold the same sample is also inspected by variable, and the sample mean is used to decide the state of the process. The distribution of the sample mean depends on the number of disapproved, because of that, the properties of their ATTRIVAR (attribute + variable) chart is not simple to obtain. Aparisi and Lee Ho (2018) proposed the M-ATTRIVAR chart to monitor the mean vector. At each sampling point, the M-ATTRIVAR works with an attribute chart or with a variable chart: if the attribute chart gives a warning signal, the control is tightened because it is replaced by the variable chart. On other hand, if the variable chart doesn't confirm the warning signal, the control is relaxed with the return of the attribute chart. Quinino, Bessegato, and Cruz (2017) extended the work of Quinino et al. (2015), now a go-no-go gauge classifies the sample items in five categories. Their monitoring statistic is a function of $d_{\mathrm{i}}(i=1,2 \ldots 5)$, the number of items in each category. The performance of their control chart enhances with the number of categories, however, the difficulty to deal with more than five categories doesn't justify the gain in performance. Following the same trend, Aparisi, Epprecht, and Mosquera (2018), Mosquera, Aparisi, and Epprecht (2018) and Bezerra, Ho, and Quinino (2018) classify the sample items in three categories. The charts proposed by Aparisi et al. (2018) and by Mosquera, Aparisi, and Epprecht (2018) were designed to compete with the joint $\bar{X}-S^{2}$ charts, and the chart proposed by Bezerra et al. (2018) was designed to compete with the $S^{2}$ control chart.

The idea of designing attribute charts to control the mean vector of bivariate processes is recent. Ho and Costa (2015) classify the units of the samples as first, second, and third class units. Their two monitoring statistics are $M=N_{1}+N_{2}$ and $W=N_{1}+2 N_{2}$, where $N_{1}$ is the number of sample units with a second-class classification and $N_{2}$ is the number of sample units with a third-class classification. The main conclusion is that the synthetic charts based on $M$ and $W$ statistics require twice larger samples to outperform the $T^{2}$ chart. Melo, Ho and Medeiros (2017b) proposed the Max $D$ chart to control the mean of bivariate processes. Their monitoring statistic is the $\operatorname{Max} D=\left\{D_{\mathrm{x}}, D_{\mathrm{y}}\right\}$, where $D_{\mathrm{x}}=n_{11}+n_{10}$, and $D_{\mathrm{y}}=n_{11}+n_{01}$, with $\mathrm{n}_{11}$ being the number of disapproved sample items with regard to both, the $X$ and $Y$ discriminate limits, $\mathrm{n}_{10}\left(\mathrm{n}_{01}\right)$ being the number of disapproved sample items with regard to the $X(Y)$ discriminate limits. Melo, Ho, and Medeiros (2017a) proposed the Max $D-T^{2}$ chart to control mean vectors. The sample is split into two subsamples; during the first stage, the Max D chart works with the first subsample to decide if the process is in control or if the inspection should go to the second stage. During the second stage, a $T^{2}$ chart works with the second subsample to decide the state of the process. In a recent paper, Machado, Ho and Costa (2018) investigated the ability of the Max $D$ chart in signaling changes in the bivariate covariance matrix.

The paper is organized as follows. The ACS $m p$ chart is introduced in Section 2, including its properties. In Section 3, the ACS $m p$ chart is compared with the standard $T^{2}$ chart, the Max $D$ chart, and with the combined Max $D-T^{2}$ chart. A real illustrative example is given in Section 4. Finally, in Section 5 we present the main conclusions.

\section{The ACS mp chart}

In this article, we combined the Alternated Charting Statistic (ACS) scheme proposed by Leoni and Costa (2017) with the attribute $n p$ chart to control mean vectors $\left(\mu_{x} ; \mu_{y}\right)^{\prime}$ of bivariate normal processes. The proposed bivariate ACS chart works with samples of size $m \leq 2 n$, where $n$ is the sample size of the competing $T^{2}$ and pure $\operatorname{Max} D$ charts. According to the ACS scheme, only one of the two quality characteristics $(X, Y)$ is measured in an alternating fashion. That is, if $X$ was the chosen quality characteristic to obtain the current sample point (given by the number of disapproved items with regard to the $X$ discriminate limits), then $Y$ will be the quality characteristic to obtain the next sample point (given by the number of disapproved items with regard to the $Y$ discriminate limits).

As in Melo et al. (2017b), the disapproved item is not necessarily nonconforming or defective, it is just an item with its ith quality characteristic $(i=x, y)$ beyond the lower and the upper discriminating limits $\left(L D_{i} ; U D_{i}\right)$. The standardized discriminating limits are given by $\left[S L D=\left(L D_{i}-\mu_{0 i}\right) / \sigma_{i} ; S U D=\left(U D_{i}-\mu_{0 i}\right) / \sigma_{i}\right]$, where $\left(\mu_{0 x} ; \mu_{0 y}\right)^{\prime}$ is the incontrol mean vector, and $\left(\sigma_{x} ; \sigma_{y}\right)$ are the standard deviations of the $X$ and $Y$ quality characteristics. If the sample points $-j=\{1,3,5, \ldots\}$ are, according to the $X$ discriminate limits, the number of disapproved sample items, then the sample points $-j=\{2,4,6, \ldots\}$ will also be the number of disapproved sample items, but now with regard to the $Y$ discriminate limits. As the number of disapproved items from the odd samples is associated with the $x_{s}$ values, and the number of disapproved items from the even samples is associated with the $y_{\mathrm{s}}$ values, the $X$ and $Y$ correlation doesn't affect the performance of the ACS mp chart.

The ACS $m p$ chart can be used to control high-quality processes where the occurrence of defective items is pretty low because the ACS chart doesn't work with defectives but with disapproved items, that rarely are defectives. The discriminating limits are adjusted to give an adequate in-control rate of disapproved items.

Fig. 1 illustrates the ACS $m p$ control chart; the odd points are related to the $x_{\mathrm{s}}$ values and the even points are related to the $y_{\mathrm{s}}$ values. The control limit of the ACS chart is $C L=D+0.5$, that means, the ACS $m p$ control chart signals whenever the number of disapproved sample items (d) exceeds $D$. The $D$ value is a function of the false alarm risk, $\alpha$ :

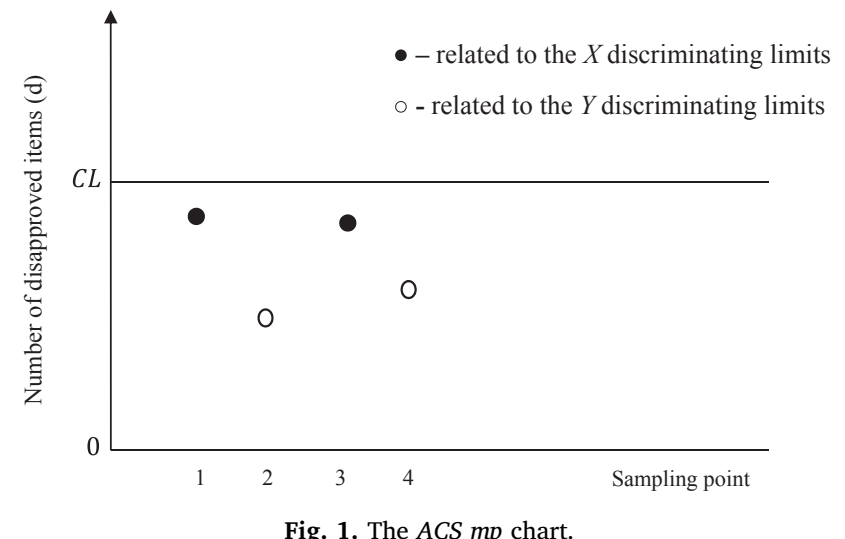

Fig. 1. The ACS $m p$ chart. 
Table 1

The ARL values for the ACS $m p$ chart, Max $D$ and the $T^{2}$ chart with $n=4$.

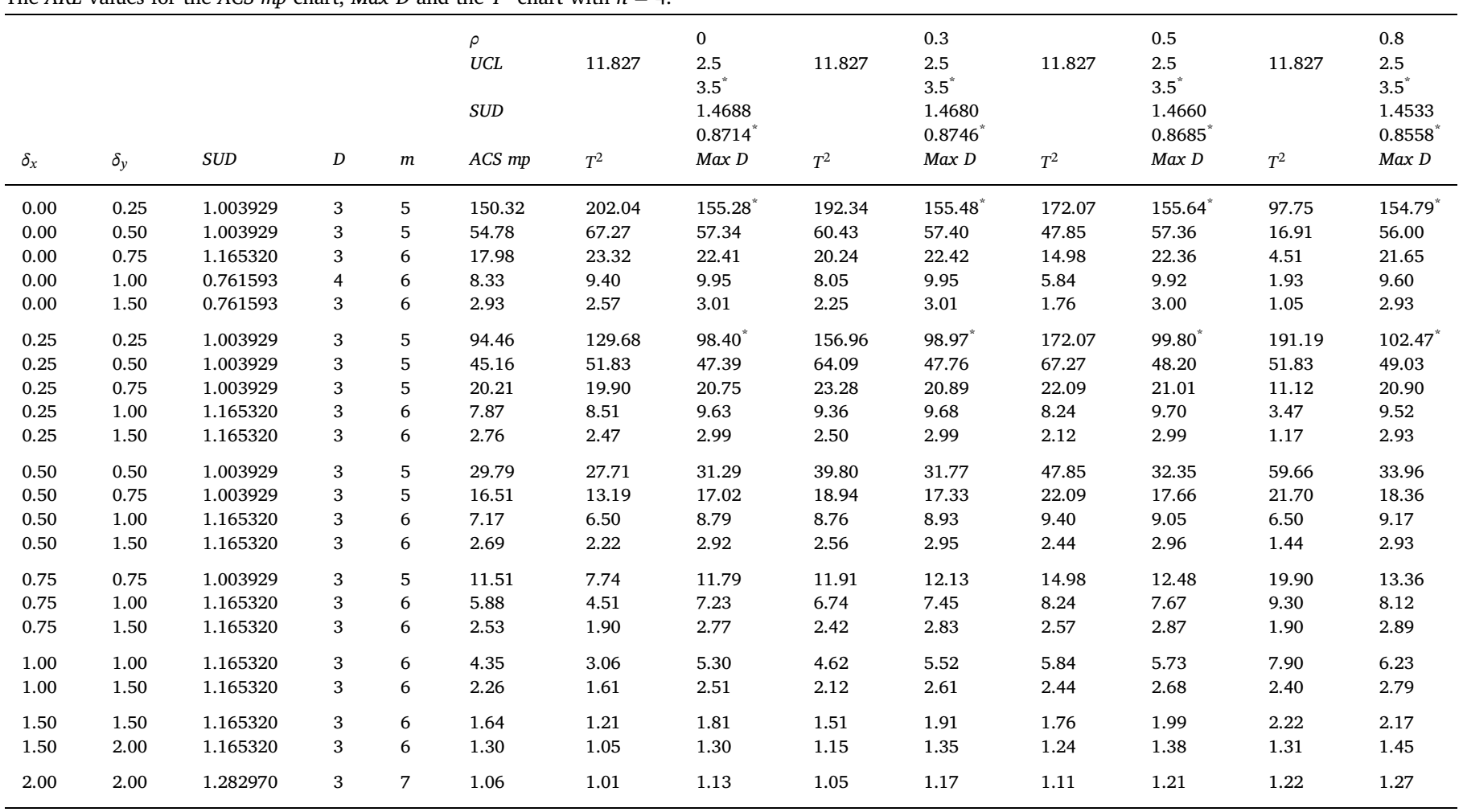

$\alpha=\sum_{i=D+1}^{m}\left(\begin{array}{c}m \\ i\end{array}\right) p_{0}^{i}\left(1-p_{0}\right)^{m-i}$, with, $p_{0}$

$=\operatorname{Pr}[S L D<Z<S U D \mid Z \sim \mathrm{N}(0 ; 1)]$

After the assignable cause occurrence, the in-control mean vector $\mu_{0}=\left(\mu_{0 x}, \mu_{0 y}\right)^{\prime}$ changes to $\mu_{1}=\left(\mu_{1 x}, \mu_{1 y}\right)^{\prime}$. The mean shift vector $\delta=\left(\delta_{x} \sigma_{x}, \delta_{y} \sigma_{y}\right)^{\prime}=\left(\mu_{1 x}-\mu_{0 x}, \mu_{1 y}-\mu_{0 y}\right)^{\prime}$. The power of the ACS mp chart depends on the quality characteristic in use to obtain the $(d)$ value

$$
\begin{aligned}
p_{i} & =\sum_{j=D+1}^{m}\left(\begin{array}{c}
m \\
j
\end{array}\right) p_{1 i}^{j}\left(1-p_{1 i}\right)^{m-j}, \text { with, } p_{1 i} \\
& =\operatorname{Pr}\left[S L D<Z<S U D \mid Z \sim \mathrm{N}\left(\delta_{i} ; 1\right)\right], \quad i=x, y
\end{aligned}
$$

The speed with which the control charts signal is measured by the Average Run Length - ARL. Expression (3) gives the ARLs of the ACS mp chart, see Appendix for details.

$A R L=\frac{4-\left(p_{x}+p_{y}\right)}{2\left(p_{x}+p_{y}-p_{x} p_{y}\right)}$

where $p_{X}\left(p_{Y}\right)$ is the power of the ACS $m p$ chart when the sample items are classified according to the $X(Y)$ discriminating limits.

The idea of working with only one quality characteristic per time, in an alternating fashion, can also be applied to control the trivariate mean vector $\left(\mu_{x} ; \mu_{y} ; \mu_{z}\right)^{\prime}$. The ARLs of the ACS $m p$ chart for the trivariate case is given by, see Appendix for details:

$A R L=\frac{9-3\left(p_{x}+p_{y}+p_{z}\right)+\left(p_{x} p_{y}+p_{x} p_{z}+p_{y} p_{z}\right)}{3\left(p_{x}+p_{y}+p_{z}-p_{x} p_{y}-p_{x} p_{z}-p_{y} p_{z}+p_{x} p_{y} p_{z}\right)}$

where $p_{X}\left(p_{Y}\right.$ or $\left.p_{Z}\right)$ is the power of the ACS $m p$ chart when the sample items are classified according to the $X(Y$ or $Z)$ discriminating limits.

The seven steps for the implementation and use of the bivariate ACS $m p$ chart are:

- Step 1. Estimate the parameters of the $X$ and $Y$ distributions.

- Step 2. Determine the discriminating limits, $U D_{x}$ and $U D_{y}$.
- Step 3. Determine the design parameters ( $m, C L)$.

- Step 4. Select the first sample and, by random, define the quality characteristic to be inspected. If $X$ is the quality characteristic go to Step 5, otherwise go to Step 6.

- Step 5. The $m$ sample items are classified as approved - disapproved according to the discriminating limit $U D_{x}$. Let $(d)$ be the number of disapproved items. If $d<C L$, wait for the next sampling point to take a new sample of size $m$; after that, go to Step 6. Otherwise, if $d>C L$, go to Step 7 .

- Step 6. The $m$ sample items are classified as approved - disapproved according to the discriminating limit $U D_{y}$. Let $(d)$ be the number of disapproved items. If $d<C L$, wait for the next sampling point to take a new sample of size $m$; after that, go to Step 5. Otherwise, if $d>C L$, go to Step 7 .

- Step 7. Investigate the existence of assignable causes.

The steps for the implementation and use of the trivariate ACS $m p$ chart are pretty similar.

\section{Comparing the charts performance}

In this section, the average run length $(A R L)$ is used to compare the performance of the ACS $m p$ chart with the performance of the standard $T^{2}$ chart and with the performance of the Max $D$ chart proposed by Melo et al. (2017b). When the process is in-control, the $A R L$ measures the rate of false alarms. A chart with a larger in-control $A R L$ has a lower false alarm rate than other charts. A chart with a smaller out-of-control $A R L$ has a better ability to detect process changes than other charts. For a fair comparison, the three control charts were designed to have the same in-control $A R L(A R L=370)$, and $m \leq 2 n$, where $n$ is the size of the samples when the $T^{2}$ chart and the pure Max $D$ chart are in use. The $m \leq 2 n$ condition lies in the fact that, at each sampling point, the ACS $m p$ chart requires the inspection of only one quality characteristic; the other bivariate charts always require the measurement of the two quality characteristics. 
Table 2

The ARL values for the ACS $m p$ chart, Max $D$ and the $T^{2}$ chart with $n=5$.

\begin{tabular}{|c|c|c|c|c|c|c|c|c|c|c|c|c|c|}
\hline \multirow[b]{4}{*}{$\delta_{x}$} & \multirow[b]{4}{*}{$\delta_{y}$} & \multirow[b]{4}{*}{ SUD } & \multirow[b]{4}{*}{$D$} & \multirow[b]{4}{*}{$m$} & \multirow{4}{*}{$\begin{array}{l}\rho \\
U C L \\
S U D \\
A C S m p\end{array}$} & \multirow{4}{*}{$\begin{array}{l}11.827 \\
T^{2}\end{array}$} & \multirow{4}{*}{$\begin{array}{l}0 \\
3.5 \\
1.1176 \\
\operatorname{Max} D\end{array}$} & \multirow{3}{*}{11.827} & \multicolumn{2}{|l|}{0.3} & \multicolumn{2}{|l|}{0.5} & \multirow{4}{*}{$\begin{array}{l}0.8 \\
3.5 \\
1.1050 \\
\operatorname{Max} D\end{array}$} \\
\hline & & & & & & & & & 3.5 & 11.827 & 3.5 & 11.827 & \\
\hline & & & & & & & & & 1.1169 & & 1.1153 & & \\
\hline & & & & & & & & $T^{2}$ & $\operatorname{Max} D$ & $T^{2}$ & $\operatorname{Max} D$ & $T^{2}$ & \\
\hline 0.00 & 0.25 & 0.761593 & 4 & 6 & 138.52 & 178.87 & 139.13 & 168.93 & 139.30 & 148.55 & 139.43 & 78.37 & 138.53 \\
\hline 0.00 & 0.50 & 0.924175 & 4 & 7 & 40.12 & 51.83 & 46.07 & 46.09 & 46.12 & 35.76 & 46.07 & 11.85 & 45.04 \\
\hline 0.00 & 0.75 & 1.282970 & 3 & 7 & 15.55 & 16.59 & 16.94 & 14.29 & 16.94 & 10.45 & 16.90 & 3.17 & 16.42 \\
\hline 0.00 & 1.00 & 0.924175 & 4 & 7 & 6.62 & 6.50 & 7.37 & 5.56 & 7.37 & 4.06 & 7.35 & 1.50 & 7.16 \\
\hline 0.00 & 1.50 & 1.044067 & 4 & 8 & 2.13 & 1.90 & 2.34 & 1.70 & 2.34 & 1.40 & 2.34 & 1.01 & 2.30 \\
\hline 0.25 & 0.25 & 0.761593 & 4 & 6 & 85.36 & 107.62 & 85.82 & 133.69 & 86.39 & 148.55 & 87.15 & 167.76 & 89.51 \\
\hline 0.25 & 0.50 & 0.924175 & 4 & 7 & 33.42 & 38.99 & 38.31 & 49.16 & 38.64 & 51.83 & 39.01 & 38.99 & 39.72 \\
\hline 0.25 & 0.75 & 0.924175 & 4 & 7 & 13.73 & 14.04 & 15.80 & 16.55 & 15.92 & 15.66 & 16.01 & 7.70 & 15.95 \\
\hline 0.25 & 1.00 & 0.924175 & 4 & 7 & 6.43 & 5.88 & 7.17 & 6.47 & 7.21 & 5.70 & 7.22 & 2.49 & 7.11 \\
\hline 0.25 & 1.50 & 1.044067 & 4 & 8 & 2.11 & 1.84 & 2.33 & 1.86 & 2.33 & 1.62 & 2.33 & 1.06 & 2.30 \\
\hline 0.50 & 0.50 & 0.924175 & 4 & 7 & 21.43 & 19.90 & 24.79 & 29.31 & 25.22 & 35.76 & 25.72 & 45.45 & 27.08 \\
\hline 0.50 & 0.75 & 0.924175 & 4 & 7 & 11.26 & 9.16 & 12.99 & 13.33 & 13.25 & 15.66 & 13.51 & 15.37 & 14.09 \\
\hline 0.50 & 1.00 & 0.924175 & 4 & 7 & 5.87 & 4.51 & 6.58 & 6.05 & 6.69 & 6.50 & 6.78 & 4.51 & 6.88 \\
\hline 0.50 & 1.50 & 1.044067 & 4 & 8 & 2.06 & 1.68 & 2.28 & 1.90 & 2.30 & 1.82 & 2.31 & 1.21 & 2.29 \\
\hline 0.75 & 0.75 & 0.924175 & 4 & 7 & 7.74 & 5.35 & 8.91 & 8.26 & 9.19 & 10.45 & 9.48 & 14.04 & 10.19 \\
\hline 0.75 & 1.00 & 0.924175 & 4 & 7 & 4.82 & 3.17 & 5.42 & 4.67 & 5.60 & 5.70 & 5.77 & 6.43 & 6.13 \\
\hline 0.75 & 1.50 & 1.044067 & 4 & 8 & 1.94 & 1.48 & 2.18 & 1.81 & 2.22 & 1.90 & 2.25 & 1.48 & 2.27 \\
\hline 1.00 & 1.00 & 0.924175 & 4 & 7 & 3.58 & 2.22 & 3.99 & 3.24 & 4.17 & 4.06 & 4.33 & 5.46 & 4.71 \\
\hline 1.00 & 1.50 & 0.924175 & 4 & 7 & 1.96 & 1.30 & 1.99 & 1.62 & 2.06 & 1.82 & 2.11 & 1.79 & 2.20 \\
\hline 1.00 & 2.00 & 1.044067 & 4 & 8 & 1.38 & 1.05 & 1.26 & 1.12 & 1.28 & 1.14 & 1.29 & 1.05 & 1.30 \\
\hline 1.50 & 1.50 & 0.924175 & 4 & 7 & 1.46 & 1.08 & 1.49 & 1.24 & 1.56 & 1.40 & 1.62 & 1.68 & 1.76 \\
\hline 1.50 & 2.00 & 1.044067 & 4 & 8 & 1.15 & 1.01 & 1.16 & 1.05 & 1.19 & 1.10 & 1.22 & 1.14 & 1.26 \\
\hline 2.00 & 2.00 & 1.282970 & 3 & 7 & 1.06 & 1.00 & 1.06 & 1.01 & 1.08 & 1.03 & 1.10 & 1.09 & 1.15 \\
\hline
\end{tabular}

Tables 1-3 present the bivariate ARLs of the ACS mp, the Max D and the $T^{2}$ charts. In all these tables, $m$ is the minimum sample size the ACS $m p$ chart requires to outperform the Max D chart. The ARLs of the Max $D$ and the $T^{2}$ charts are function of $\rho$, the correlation between $X$ and $Y$ quality characteristics. In Tables $1-3$, the $(X, Y)$ variables were considered uncorrelated $(\rho=0)$, or correlated with $\rho=0.3,0.5$, or 0.7 .
With the alternated charting statistic (ACS), the $X$ observations are from odd samples and the $Y$ observations are from even samples or vice versa, consequently, the number of disapproved sample items $(d)$ is not affected by the correlation between $X$ and $Y$ quality characteristics, see Leoni and Costa (2017).

Following the assumptions adopted by Sampaio et al. (2014) and by

Table 3

The ARL values for the ACS $m p$ chart, $\operatorname{Max} D$ and the $T^{2}$ chart with $n=6$.

\begin{tabular}{|c|c|c|c|c|c|c|c|c|c|c|c|c|c|}
\hline \multirow[b]{5}{*}{$\delta_{x}$} & \multirow[b]{5}{*}{$\delta_{y}$} & \multirow[b]{5}{*}{ SUD } & \multirow[b]{5}{*}{$D$} & \multirow[b]{5}{*}{$m$} & \multirow{4}{*}{$\begin{array}{l}\rho \\
U C L \\
S U D\end{array}$} & \multirow{4}{*}{11.827} & \multicolumn{2}{|l|}{0} & \multicolumn{2}{|l|}{0.3} & \multicolumn{2}{|l|}{0.5} & \multirow{5}{*}{$\begin{array}{l}0.8 \\
3.5 \\
4.5^{*} \\
1.2612 \\
0.8557 \\
\text { Max D }\end{array}$} \\
\hline & & & & & & & $\begin{array}{l}3.5 \\
4.5^{*}\end{array}$ & 11.827 & $\begin{array}{l}3.5 \\
4.5^{*}\end{array}$ & 11.827 & $\begin{array}{l}3.5 \\
4.5^{*}\end{array}$ & 11.827 & \\
\hline & & & & & & & 1.2722 & & 1.2726 & & 1.2702 & & \\
\hline & & & & & & & $0.8665^{*}$ & & $0.8658^{*}$ & & $0.8644^{*}$ & & \\
\hline & & & & & $A C S m p$ & $T^{2}$ & $\operatorname{Max} D$ & $T^{2}$ & $\operatorname{Max} D$ & $T^{2}$ & $\operatorname{Max} D$ & $T^{2}$ & \\
\hline 0.00 & 0.25 & 0.924175 & 4 & 7 & 127.96 & 159.63 & $126.96^{*}$ & 36.29 & $127.12^{*}$ & 129.68 & $127.22^{*}$ & 64.25 & $126.37^{*}$ \\
\hline 0.00 & 0.50 & 0.737438 & 5 & 8 & 35.03 & 41.15 & $38.81^{*}$ & 10.64 & $38.85^{*}$ & 27.71 & $38.80^{*}$ & 8.79 & $37.97^{*}$ \\
\hline 0.00 & 0.75 & 1.044067 & 4 & 8 & 12.60 & 12.41 & $13.71^{*}$ & 4.13 & $13.71^{*}$ & 7.74 & $13.68^{*}$ & 2.42 & $13.33^{*}$ \\
\hline 0.00 & 1.00 & 1.044067 & 4 & 8 & 5.61 & 4.82 & 5.87 & 1.41 & 5.87 & 3.06 & 5.85 & 1.28 & 5.71 \\
\hline 0.00 & 1.50 & 0.954496 & 5 & 10 & 1.82 & 1.55 & 1.91 & 1.04 & 1.91 & 1.21 & 1.90 & 1.00 & 1.88 \\
\hline 0.25 & 0.25 & 0.924175 & 4 & 7 & 77.51 & 90.82 & $76.78^{*}$ & 38.88 & $77.33^{*}$ & 129.68 & $78.05^{*}$ & 148.55 & $80.27^{*}$ \\
\hline 0.25 & 0.50 & 1.375327 & 3 & 8 & 32.54 & 30.38 & $32.45^{*}$ & 12.38 & $32.74^{*}$ & 41.15 & $33.06^{*}$ & 30.38 & $33.69^{*}$ \\
\hline 0.25 & 0.75 & 0.424845 & 6 & 8 & 12.83 & 10.45 & $12.86^{*}$ & 4.79 & $12.95^{*}$ & 11.70 & $13.03^{*}$ & 5.70 & $12.99^{*}$ \\
\hline 0.25 & 1.00 & 1.044067 & 4 & 8 & 5.46 & 4.37 & 5.73 & 1.51 & 5.76 & 4.23 & 5.77 & 1.95 & 5.68 \\
\hline 0.25 & 1.50 & 0.954496 & 5 & 10 & 1.81 & 1.50 & 1.90 & 1.05 & 1.90 & 1.36 & 1.90 & 1.02 & 1.88 \\
\hline 0.50 & 0.50 & 1.375327 & 3 & 8 & 18.93 & 14.98 & $20.71^{*}$ & 9.91 & $21.10^{*}$ & 27.71 & $21.53^{*}$ & 35.76 & $22.74^{*}$ \\
\hline 0.50 & 0.75 & 1.375327 & 3 & 8 & 10.69 & 6.78 & $10.59^{*}$ & 4.49 & $10.82^{*}$ & 11.70 & $11.04^{*}$ & 11.47 & $11.53^{*}$ \\
\hline 0.50 & 1.00 & 1.044067 & 4 & 8 & 5.01 & 3.37 & 5.29 & 1.54 & 5.38 & 4.82 & 5.45 & 3.37 & 5.52 \\
\hline 0.50 & 1.50 & 1.217258 & 4 & 10 & 1.79 & 1.40 & 1.87 & 1.06 & 1.88 & 1.49 & 1.89 & 1.10 & 1.88 \\
\hline 0.75 & 0.75 & 1.044067 & 4 & 8 & 6.65 & 3.98 & $7.23^{*}$ & 3.49 & $7.48^{*}$ & 7.74 & $7.72^{*}$ & 10.45 & $8.32^{*}$ \\
\hline 0.75 & 1.00 & 1.044067 & 4 & 8 & 4.13 & 2.42 & 4.38 & 1.48 & 4.54 & 4.23 & 4.67 & 4.76 & 4.95 \\
\hline 0.75 & 1.50 & 1.138927 & 4 & 9 & 1.79 & 1.27 & 1.79 & 1.06 & 1.83 & 1.55 & 1.85 & 1.27 & 1.86 \\
\hline 0.75 & 2.00 & 1.044067 & 4 & 8 & 1.48 & 1.03 & 1.15 & 2.48 & 1.16 & 1.05 & 1.16 & 1.00 & 1.16 \\
\hline 1.00 & 1.00 & 1.044067 & 4 & 8 & 3.07 & 1.76 & 3.23 & 1.36 & 3.38 & 3.06 & 3.52 & 4.06 & 3.82 \\
\hline 1.00 & 1.50 & 1.138927 & 4 & 9 & 1.60 & 1.16 & 1.65 & 1.05 & 1.71 & 1.49 & 1.75 & 1.47 & 1.82 \\
\hline 1.50 & 1.50 & 1.451146 & 3 & 9 & 1.28 & 1.03 & 1.29 & 1.02 & 1.35 & 1.21 & 1.40 & 1.40 & 1.49 \\
\hline 1.50 & 2.00 & 1.283810 & 4 & 11 & 1.05 & 1.00 & 1.07 & 1.00 & 1.10 & 1.04 & 1.11 & 1.06 & 1.14 \\
\hline 2.00 & 2.00 & 1.451146 & 3 & 9 & 1.02 & 1.00 & 1.02 & 149.71 & 1.03 & 1.01 & 1.04 & 1.03 & 1.07 \\
\hline
\end{tabular}


Table 4

The ARL values for the trivariate ACS $m p, T^{2}$, and $\operatorname{Max} D$ charts with $n=4$.

\begin{tabular}{|c|c|c|c|c|c|c|c|c|c|c|c|c|c|c|c|c|c|}
\hline \multirow[b]{4}{*}{$\delta_{x}$} & \multirow[b]{4}{*}{$\delta_{y}$} & \multirow[b]{4}{*}{$\delta_{z}$} & \multirow{3}{*}{\multicolumn{2}{|c|}{$\begin{array}{l}\rho_{x y} \\
\rho_{x z} \\
\rho_{y z}\end{array}$}} & \multirow[b]{4}{*}{$\begin{array}{l}S U D \\
U C L \\
A C S m p\end{array}$} & \multirow{3}{*}{\multicolumn{2}{|c|}{$\begin{array}{l}0.0 \\
0.0 \\
0.0\end{array}$}} & & & & & \\
\hline & & & & & & & & 0.5 & & 0.7 & & 0.5 & & 0.3 & & 0.7 & \\
\hline & & & & & & & & 0.5 & & 0.7 & & 0.7 & & 0.7 & & 0.7 & \\
\hline & & & SUD & $\begin{array}{l}D=4 \\
m\end{array}$ & & $\begin{array}{l}14.1541 \\
T^{2}\end{array}$ & $\begin{array}{l}1.5396 \\
2.5 \\
\operatorname{Max} D\end{array}$ & $\begin{array}{l}14.1541 \\
T^{2}\end{array}$ & $\begin{array}{l}1.5352 \\
2.5 \\
\operatorname{Max} D\end{array}$ & $\begin{array}{l}14.1541 \\
T^{2}\end{array}$ & $\begin{array}{l}1.5255 \\
2.5 \\
\operatorname{Max} D\end{array}$ & $\begin{array}{l}14.1541 \\
T^{2}\end{array}$ & $\begin{array}{l}1.5328 \\
2.5 \\
\operatorname{Max} D\end{array}$ & $\begin{array}{l}14.1541 \\
T^{2}\end{array}$ & $\begin{array}{l}1.5339 \\
2.5 \\
\operatorname{Max} D\end{array}$ & $\begin{array}{l}14.1541 \\
T^{2}\end{array}$ & $\begin{array}{l}1.5294 \\
2.5 \\
\operatorname{Max} D\end{array}$ \\
\hline 0 & 0 & 0.5 & 0.76160 & 6 & 66.1 & 85.8 & 73.6 & 53.8 & 73.6 & 28.7 & 72.5 & 28.1 & 73.7 & 36.7 & 73.6 & 12.0 & 73.6 \\
\hline 0 & 0 & 0.75 & 0.76160 & 6 & 26.3 & 30.8 & 28.5 & 16.4 & 28.4 & 7.6 & 27.8 & 7.4 & 28.4 & 10.1 & 28.4 & 3.0 & 28.2 \\
\hline 0 & 0 & 1 & 0.92417 & 7 & 9.6 & 12.3 & 12.3 & 6.1 & 12.2 & 2.9 & 11.9 & 2.8 & 12.2 & 3.8 & 12.2 & 1.4 & 12.1 \\
\hline 0 & 0 & 1.5 & 0.92417 & 7 & 3.4 & 3.1 & 3.4 & 1.7 & 3.4 & 1.2 & 3.4 & 1.2 & 3.4 & 1.3 & 3.4 & 1.0 & 3.4 \\
\hline 0 & 0.5 & 0.5 & 0.76160 & 6 & 36.5 & 36.6 & 41.0 & 36.6 & 42.2 & 22.4 & 42.9 & 55.0 & 42.0 & 63.1 & 41.2 & 37.5 & 43.4 \\
\hline 0 & 0.5 & 0.75 & 0.76160 & 6 & 20.0 & 17.4 & 21.9 & 16.4 & 22.6 & 9.2 & 22.9 & 19.6 & 22.5 & 26.8 & 22.1 & 8.8 & 23.2 \\
\hline 0 & 0.5 & 1 & 0.76160 & 6 & 10.6 & 8.4 & 10.9 & 7.1 & 11.2 & 3.8 & 11.2 & 6.6 & 11.1 & 9.6 & 11.0 & 2.7 & 11.3 \\
\hline 0 & 0.5 & 1.5 & 0.92417 & 7 & 3.2 & 2.6 & 3.4 & 2.0 & 3.4 & 1.3 & 3.3 & 1.6 & 3.4 & 2.0 & 3.4 & 1.1 & 3.4 \\
\hline 0 & 0.75 & 0.75 & 0.76160 & 6 & 13.9 & 10.1 & 15.1 & 10.1 & 15.8 & 5.7 & 16.3 & 16.8 & 15.7 & 20.2 & 15.3 & 10.4 & 16.5 \\
\hline 0 & 0.75 & 1 & 0.76160 & 6 & 8.7 & 5.7 & 9.0 & 5.5 & 9.5 & 3.1 & 9.7 & 7.5 & 9.4 & 10.3 & 9.1 & 3.6 & 9.8 \\
\hline 0 & 0.75 & 1.5 & 0.92417 & 7 & 3.0 & 2.2 & 3.2 & 2.0 & 3.3 & 1.3 & 3.3 & 1.8 & 3.3 & 2.5 & 3.2 & 1.1 & 3.3 \\
\hline 0 & 1 & 1 & 0.76160 & 6 & 6.4 & 3.8 & 6.5 & 3.8 & 7.0 & 2.3 & 7.2 & 6.3 & 6.9 & 7.7 & 6.7 & 3.9 & 7.3 \\
\hline 0 & 1 & 1.5 & 0.92417 & 7 & 2.7 & 1.8 & 2.9 & 1.7 & 3.1 & 1.3 & 3.1 & 2.0 & 3.0 & 2.7 & 3.0 & 1.2 & 3.1 \\
\hline 0 & 1.5 & 1.5 & 0.92417 & 7 & 2.0 & 1.3 & 2.0 & 1.3 & 2.2 & 1.1 & 2.3 & 1.8 & 2.2 & 2.1 & 2.1 & 1.3 & 2.3 \\
\hline 0.5 & 0.5 & 0.5 & 0.76160 & 6 & 25.3 & 19.8 & 28.6 & 53.8 & 30.2 & 67.1 & 31.6 & 51.4 & 30.4 & 47.7 & 30.1 & 51.0 & 30.9 \\
\hline 0.5 & 0.5 & 0.75 & 0.76160 & 6 & 16.2 & 11.1 & 17.9 & 28.5 & 19.0 & 30.7 & 19.8 & 29.2 & 19.3 & 24.7 & 19.0 & 30.5 & 19.7 \\
\hline 0.5 & 0.5 & 1 & 0.76160 & 6 & 9.5 & 6.1 & 9.9 & 12.3 & 10.4 & 10.3 & 10.6 & 10.8 & 10.5 & 9.8 & 10.4 & 8.4 & 10.7 \\
\hline 0.5 & 0.5 & 1.5 & 0.92417 & 7 & 3.1 & 2.3 & 3.3 & 2.9 & 3.3 & 2.0 & 3.3 & 2.1 & 3.4 & 2.2 & 3.3 & 1.4 & 3.4 \\
\hline 0.5 & 0.75 & 0.75 & 0.76160 & 6 & 11.9 & 7.1 & 13.1 & 19.8 & 14.1 & 22.4 & 14.9 & 22.6 & 14.2 & 21.0 & 13.8 & 23.7 & 14.7 \\
\hline 0.5 & 0.75 & 1 & 0.76160 & 6 & 7.9 & 4.4 & 8.3 & 10.6 & 8.9 & 10.2 & 9.3 & 12.2 & 9.0 & 11.4 & 8.8 & 10.8 & 9.3 \\
\hline 0.5 & 0.75 & 1.5 & 0.92417 & 7 & 3.0 & 2.0 & 3.1 & 2.9 & 3.3 & 2.2 & 3.3 & 2.6 & 3.3 & 2.7 & 3.2 & 1.7 & 3.3 \\
\hline 0.5 & 1 & 1 & 0.76160 & 6 & 6.0 & 3.1 & 6.1 & 7.1 & 6.7 & 6.7 & 7.1 & 9.3 & 6.7 & 9.0 & 6.5 & 9.1 & 7.1 \\
\hline 0.5 & 1 & 1.5 & 0.92417 & 7 & 2.6 & 1.7 & 2.8 & 2.6 & 3.0 & 2.1 & 3.1 & 2.9 & 3.0 & 3.1 & 3.0 & 2.0 & 3.1 \\
\hline 0.5 & 1.5 & 1.5 & 0.92417 & 7 & 1.9 & 1.3 & 2.0 & 1.7 & 2.2 & 1.5 & 2.3 & 2.4 & 2.2 & 2.4 & 2.1 & 2.1 & 2.3 \\
\hline 0.75 & 0.75 & 0.75 & 0.76160 & 6 & 9.5 & 5.0 & 10.4 & 16.4 & 11.4 & 21.9 & 12.2 & 15.5 & 11.5 & 14.0 & 11.3 & 15.3 & 11.8 \\
\hline 0.75 & 0.75 & 1 & 0.76160 & 6 & 6.8 & 3.4 & 7.1 & 10.1 & 7.9 & 12.2 & 8.4 & 10.6 & 8.0 & 8.7 & 7.9 & 12.0 & 8.3 \\
\hline 0.75 & 0.75 & 1.5 & 0.92417 & 7 & 2.8 & 1.7 & 3.0 & 3.1 & 3.2 & 2.6 & 3.2 & 2.8 & 3.2 & 2.5 & 3.2 & 2.2 & 3.2 \\
\hline 0.75 & 1 & 1 & 0.76160 & 6 & 5.4 & 2.5 & 5.5 & 7.4 & 6.2 & 9.2 & 6.6 & 8.0 & 6.2 & 7.3 & 6.0 & 8.6 & 6.5 \\
\hline 0.75 & 1 & 1.5 & 0.92417 & 7 & 2.5 & 1.5 & 2.7 & 2.9 & 3.0 & 2.7 & 3.1 & 3.1 & 3.0 & 2.9 & 2.9 & 2.7 & 3.1 \\
\hline 0.75 & 1.5 & 1.5 & 0.92417 & 7 & 1.9 & 1.2 & 2.0 & 2.0 & 2.2 & 1.9 & 2.3 & 2.4 & 2.2 & 2.4 & 2.1 & 2.4 & 2.3 \\
\hline 1 & 1 & 1 & 0.76160 & 6 & 4.5 & 2.0 & 4.5 & 6.1 & 5.2 & 8.4 & 5.6 & 5.8 & 5.2 & 5.2 & 5.1 & 5.7 & 5.4 \\
\hline 1 & 1 & 1.5 & 0.92417 & 7 & 2.3 & 1.4 & 2.5 & 2.9 & 2.8 & 3.1 & 2.9 & 2.9 & 2.9 & 2.5 & 2.8 & 3.1 & 2.9 \\
\hline 1 & 1.5 & 1.5 & 0.92417 & 7 & 1.8 & 1.1 & 1.9 & 2.0 & 2.1 & 2.3 & 2.3 & 2.3 & 2.1 & 2.1 & 2.1 & 2.4 & 2.2 \\
\hline 1.5 & 1.5 & 1.5 & 0.92417 & 7 & 1.5 & 1.1 & 1.6 & 1.7 & 1.8 & 2.2 & 2.0 & 1.7 & 1.8 & 1.6 & 1.8 & 1.7 & 1.9 \\
\hline
\end{tabular}

Melo et al. (2017a, 2017b) we also worked with only upper discriminating limits. According to Tables 1-3, the ACS $m p$ chart always outperforms the Max $D$ chart. For instance, in Table 1, if the magnitude of the disturbance is $\left(\delta_{\mathrm{x}}, \delta_{y}\right)=(0.5,1.0)$, the ACS $m p$ chart requires, on average, 7.17 samples of size $m=6$ to signal. The speed with which the Max D chart signals this type of disturbance depends on the correlation. If the variables are highly correlated $(\rho=0.8)$ the $\operatorname{Max} D$ chart requires, on average, 9.17 samples of size $n=4(2 n>m)$ to signal. This number decreases to 8.79 when the variables are uncorrelated $(\rho=0)$. The upper discriminating (SUD) and control limits (UCL) of Max D chart depend on the magnitude of the shifts. For instance, in Table 1 , if $\rho=0$ the optimum performance for $\left(\delta_{\mathrm{x}}=0\right.$ or $\left.0.25, \delta_{y}=0.25\right)$ is yielded with $C L=3.5$ and $S U D=0.871417$ (these cases are marked with $*$ ). The optimum performance for all other shifts is yielded with $C L=2.5$ and $S U D=1.468796$.

The Max D chart was proposed by Melo et al. (2017b), however, they only presented the bivariate $A R L s$. In order to compare our trivariate ACS $m p$ chart with the Max D chart, we extended their results to the trivariate case. When the trivariate $\operatorname{Max} D$ chart is in use, the monitoring statistic is the $\operatorname{Max} D=\left\{D_{\mathrm{x}}, D_{\mathrm{y}}, D_{\mathrm{z}}\right\}$, where $D_{\mathrm{x}}=n_{111}+n_{101}+n_{110}+n_{100}, \quad D_{\mathrm{y}}=n_{111}+n_{011}+n_{110}+n_{010}$, and $D_{\mathrm{z}}=n_{111}+n_{011}+n_{101}+n_{001}$, being $n_{\mathrm{ijk}}$ the number of sample items classified as approved with regard to the $X, Y$, and disapproved with regard $Z$ discriminating limits. For instance, $n_{101}$ is the number of sample items classified as disapproved with regard to the $X$ and $Z$ discriminating limits and approved with regard to the $Y$ discriminating limit.

Table 4 presents the ARLs for the trivariate ACS $m p, T^{2}$, and Max $D$ charts with $n=4$. In Table $4, m$ is the minimum sample size the trivariate ACS $m p$ chart requires to outperform the $\operatorname{Max} D$ chart. It is worth to stress that the $m$ values in Table 4 are pretty lower than the maximum $m=12(=3 n)$. The $m \leq 3 n$ condition lies in the fact that, at each sampling point, the ACS $m p$ chart requires the inspection of only one quality characteristic; the other trivariate charts always require the measurement of the three quality characteristics.

The combined attribute-variable control chart, namely Max $D-T^{2}$, works with two samples, the first sample of size $n_{1}$ is used with the Max $D$ chart and the second sample of size $n_{2}$ is used with the $T^{2}$ chart. If the 
Table 5

The ARL values for the bivariate ACS-TSS mp and Max $D-T^{2}$ charts.

\begin{tabular}{|c|c|c|c|c|c|c|}
\hline \multirow[b]{5}{*}{$\delta_{x}$} & \multirow{4}{*}{$\begin{array}{l}\text { SUD } \\
C L \\
U C L\end{array}$} & \multirow[t]{2}{*}{$\begin{array}{l}\rho \\
A N C=4 \\
m_{1}=2 ; m_{2}=12 \\
D_{1}=0 ; D_{2}=3 \\
1.3578\end{array}$} & $\begin{array}{l}0.0 \\
A S S=2 \\
n_{1}=1 \\
n_{2}=4\end{array}$ & \multirow[t]{3}{*}{$\begin{array}{l}0.3 \\
1.060\end{array}$} & \multirow[t]{3}{*}{$\begin{array}{l}0.5 \\
1.013\end{array}$} & \multirow[t]{3}{*}{$\begin{array}{l}0.8 \\
0.903\end{array}$} \\
\hline & & & 1.105 & & & \\
\hline & & & 0.5 & & & \\
\hline & & & 9.0626 & 9.0544 & 9.0566 & 9.0574 \\
\hline & $\delta y$ & ACS-TSS $m p$ & $\operatorname{Max} D-T^{2}$ & & & \\
\hline 0.00 & 0.00 & 370.0 & 370.0 & 370.0 & 370.0 & 370.0 \\
\hline 0.00 & 0.25 & 104.6 & 189.4 & 183.3 & 168.1 & 105.8 \\
\hline 0.00 & 0.50 & 27.7 & 63.2 & 58.5 & 48.4 & 20.5 \\
\hline 0.00 & 0.75 & 9.6 & 22.0 & 19.8 & 15.5 & 5.9 \\
\hline 0.00 & 1.00 & 4.5 & 8.9 & 8.0 & 6.2 & 2.7 \\
\hline 0.00 & 1.50 & 2.1 & 2.5 & 2.3 & 2.1 & 1.4 \\
\hline 0.25 & 0.25 & 61.1 & 113.6 & 135.0 & 146.9 & 162.3 \\
\hline 0.25 & 0.50 & 23.4 & 45.5 & 55.4 & 58.4 & 47.7 \\
\hline 0.25 & 0.75 & 9.0 & 17.7 & 20.6 & 20.0 & 11.5 \\
\hline 0.25 & 1.00 & 4.4 & 7.8 & 8.6 & 7.8 & 4.0 \\
\hline 0.25 & 1.50 & 2.1 & 2.4 & 2.5 & 2.2 & 1.5 \\
\hline 0.50 & 0.50 & 14.6 & 24.0 & 33.3 & 39.4 & 48.4 \\
\hline 0.50 & 0.75 & 7.4 & 11.6 & 16.0 & 18.5 & 18.6 \\
\hline 0.50 & 1.00 & 4.0 & 5.9 & 7.6 & 8.2 & 6.2 \\
\hline 0.50 & 1.50 & 2.0 & 2.1 & 2.4 & 2.4 & 1.7 \\
\hline 0.75 & 0.75 & 5.1 & 6.9 & 10.0 & 12.3 & 15.9 \\
\hline 0.75 & 1.00 & 3.3 & 4.1 & 5.8 & 6.9 & 7.8 \\
\hline 0.75 & 1.50 & 1.8 & 1.9 & 2.3 & 2.4 & 2.0 \\
\hline 1.00 & 1.00 & 2.5 & 2.9 & 4.0 & 4.9 & 6.4 \\
\hline 1.00 & 1.50 & 1.6 & 1.6 & 2.0 & 2.2 & 2.2 \\
\hline 1.50 & 1.50 & 1.3 & 1.2 & 1.5 & 1.3 & 2.0 \\
\hline
\end{tabular}

state of the process (in-control or out-of-control) is decided with the Max $D$ chart, the second sample of size $n_{2}$ is not inspected, consequently, the average sample size (ASS) is given by $n_{1}+p_{2} * n_{2}$, where $p_{2}$ is the in-control probability of requiring the $T^{2}$ chart to decide the state of the process.

Table 5 compares the ARLs of the bivariate ACS $m p$ chart with the $A R L$ s of the bivariate Max $D-T^{2}$ chart. For a fairer comparison, we developed the bivariate ACS $m p$ chart with two-stage sampling (ACS-TSS $m p$ chart). During the first stage, a sample of size $\left(m_{1}\right)$ is taken from the process and the $\left(m_{1}\right)$ sample items are classified as approved - disapproved according to the discriminating limit $U D_{x}$ (or $U D_{y}$ ), if the current classification is with regard to the $X$ (or with regard to the $Y$ ) dimension. If the number of disapproved items, found among the $\left(m_{1}\right)$ sample items, doesn't exceed the threshold $D_{1}$, the two-stage sampling doesn't go to its second stage and the process is considered to be in control. Otherwise, the two-stage sampling goes to its second stage, where a new sample of size $\left(m_{2}\right)$ is taken from the process and the $\left(m_{2}\right)$ sample items are classified as approved - disapproved according to the same discriminating limit that was used during the first stage. If the number of disapproved items, found among the $\left(m_{2}\right)$ sample items, exceeds the threshold $D_{2}$, the ACS $m p$ chart with two-stage sampling signals an out-of-control condition. Otherwise, the process is considered to be in control. With the two-stage sampling in use, the average number of classified items per sampling (ANC) is given by $A N C=m_{1}+p \times m_{2}$, where $(p)$ is the in-control probability of going to the second sampling stage to decide the state of the process.

When the bivariate ACS $m p$ chart with two-stage sampling is compared with the bivariate $\operatorname{Max} D-T^{2}$ chart, the constraint $A N C \leqslant 2 \times A S S$ should be observed. The ANC $\leqslant 2 \times A S S$ condition lies in the fact that the bivariate ACS-TSS $m p$ chart requires the measurement of only one quality characteristic of the sample items, whereas the bivariate Max D-
$T^{2}$ chart always requires the measurement of the two quality characteristics of the sample items. According to Table 5, the bivariate ACSTSS $m p$ chart always outperforms the bivariate Max $D-T^{2}$ chart, except for the cases in bold, where the variables are highly correlated $(\rho=0.8)$.

The combined Max $D-T^{2}$ chart was proposed by Melo et al. (2017a), however, they only presented the bivariate $A R L s$. In order to compare our trivariate ACS-TSS $m p$ chart with the Max $D-T^{2}$ chart, we extended their results to the trivariate case.

Table 6 presents the ARLs of the trivariate ACS $m p$ chart with twostage sampling and the Max $D-T^{2}$ chart. The ARLs of the Max $D-T^{2}$ chart depends on the values of $\rho_{\mathrm{XY}}, \rho_{\mathrm{XZ}}$, and $\rho_{\mathrm{YZ}}$, respectively the correlations between variables $(X, Y),(X, Z)$, and $(Y, Z)$. In Table 6 , the variables were considered uncorrelated or correlated with $\rho_{\mathrm{XY}}, \rho_{\mathrm{XZ}}$ and $\rho_{\mathrm{YZ}}$ assuming the values $0.3,0.5$, or 0.7 . When the trivariate ACS $m p$ chart with two-stage sampling is compared with the trivariate Max $D-T^{2}$ chart, the constraint $A N C \leqslant 3 \times A S S$ should be observed. The $A N C \leqslant 3 \times A S S$ condition lies in the fact that the trivariate ACS-TSS mp chart requires the measurement of only one quality characteristic of the sample items, whereas the trivariate $\operatorname{Max} D-T^{2}$ chart always requires the measurement of the three quality characteristics of the sample items. According to Table 6, the trivariate ACS-TSS mp chart outperforms the trivariate Max $D-T^{2}$ chart, except for less than $10 \%$ of the cases (bold $A R L s)$, most of them are in the first block of $A R L s$, where only one variable is affected by the assignable cause and at least one pair of variables are highly correlated $(\rho=0.7)$.

\section{An illustrative example}

In this section, we explain the use of the proposed ACS $m p$ chart. The two quality characteristics $(X, Y)$ are, respectively, the bigger and the smaller diameters of a solid circular bar, see Fig. 2. The $(X, Y)$ variables follow a bivariate normal distribution with the mean vector $\mu^{\prime}=\left(\mu_{0 x} ; \mu_{0 y}\right)=(56 \mathrm{~mm} ; 42 \mathrm{~mm})$, and the covariance matrix $\operatorname{COV}(X, Y)=\left[\sigma_{i, j}, i, j \in\{x, y\}\right]$, with $\sigma_{x x}=1.2113^{2}, \sigma_{y y}=1.3155^{2}$ and $\sigma_{x y}=0.8764$. The discriminating limits are set to be $U D_{x}=46.994285$ and $U D_{y}=32.629553$, that is, their standardized values are equal to $0.9242=[46.9943-56.0000] / 1.2113=[32.6296-42.0000] / 1.2113$.

The three design parameters (SUD, $m, C L$ ) of the ACS $m p$ chart are respectively $0.9242,7$, and 4.5 , see Table 3 .

At each sampling point, a sample of seven bars is collected and only one quality characteristic is measured. In Fig. 3 and Table 7, the first sample was inspected with regard to the $X$ quality characteristic; only one item of the sample was disapproved. Following the ACS scheme, the second sample was inspected with regard to the $Y$ quality characteristic; again, only one item was disapproved. According to the distribution of the samples points, we conclude that the assignable cause increased $\mu_{x}$ without affecting $\mu_{y}$. It is worth to mention that the ACS mp chart easily identifies the quality characteristic affected by the assignable cause; moreover, the covariance $\sigma_{x y}=0.8764$ was unnecessarily estimated; we cannot say the same when the process is monitored by the $T^{2}$ chart or by the Max $D$ chart.

\section{Conclusions and extensions}

In this article, we combined the alternated charting statistic scheme with the attribute $n p$ chart to control bivariate and trivariate mean vectors. According to this bivariate proposed scheme, the $X$ observations are from the odd samples and the $Y$ observations are from the even samples or vice versa. As the $X$ and $Y$ observations are not from the same samples, the dependence between the two quality characteristics 
Table 6

The $A R L$ values for the trivariate ACS-TSS $m p$ and Max $D-T^{2}$ charts.

\begin{tabular}{|c|c|c|c|c|c|c|c|c|c|}
\hline \multirow[b]{7}{*}{ SUD } & \multirow[b]{10}{*}{$\delta_{y}$} & \multirow[b]{10}{*}{$\delta_{z}$} & \multirow{6}{*}{$\begin{array}{l}\rho_{x y} \\
\rho_{x z} \\
\rho_{y z} \\
A N C=6 \\
m_{1}=4 ; m_{2}=11 \\
D_{1}=0 ; D_{2}=2\end{array}$} & 0.0 & 0.5 & 0.7 & 0.3 & 0.3 & \multirow{2}{*}{$\begin{array}{l}0.3 \\
0.7\end{array}$} \\
\hline & & & & 0.0 & & 0.7 & 0.5 & 0.3 & \\
\hline & & & & 0.0 & 0.5 & 0.7 & 0.7 & 0.7 & 0.7 \\
\hline & & & & $A S S=2$ & & & & & \\
\hline & & & & $n_{1}=1$ & & & & & \\
\hline & & & & $n_{2}=3$ & & & & & \\
\hline & & & 1.650822 & 1.143 & 0.97 & 0.863 & 0.962 & 0.99 & 0.923 \\
\hline$C L$ & & & & 0.5 & & & & & \\
\hline$U C L$ & & & & 11.799 & 11.805 & 11.796 & 11.797 & 11.796 & 11.796 \\
\hline$\delta_{x}$ & & & $A C S-T S S m p$ & $\operatorname{Max} D-T^{2}$ & & & & & \\
\hline 0 & 0 & 0.5 & 43.9 & 104.1 & 74.9 & 46.2 & 46.5 & 56.4 & 24.0 \\
\hline 0 & 0 & 0.75 & 15.0 & 41.8 & 25.9 & 13.7 & 13.9 & 17.7 & 6.6 \\
\hline 0 & 0 & 1 & 6.5 & 17.7 & 10.1 & 5.2 & 5.3 & 6.8 & 2.8 \\
\hline 0 & 0 & 1.5 & 2.6 & 4.5 & 2.7 & 1.7 & 1.7 & 2.0 & 1.4 \\
\hline 0 & 0.5 & 0.5 & 23.5 & 45.8 & 47.9 & 33.0 & 67.0 & 74.4 & 50.0 \\
\hline 0 & 0.5 & 0.75 & 11.7 & 23.2 & 23.2 & 14.6 & 27.6 & 35.1 & 14.6 \\
\hline 0 & 0.5 & 1 & 5.9 & 11.7 & 10.6 & 6.3 & 10.3 & 14.0 & 4.9 \\
\hline 0 & 0.5 & 1.5 & 2.5 & 3.7 & 3.0 & 1.9 & 2.4 & 3.0 & 1.5 \\
\hline 0 & 0.75 & 0.75 & 7.9 & 13.8 & 14.6 & 9.2 & 22.7 & 26.3 & 15.4 \\
\hline 0 & 0.75 & 1 & 4.8 & 8.0 & 8.2 & 5.1 & 10.9 & 14.1 & 5.8 \\
\hline 0 & 0.75 & 1.5 & 2.4 & 3.0 & 2.8 & 1.9 & 2.7 & 3.6 & 1.6 \\
\hline 0 & 1 & 1 & 3.6 & 5.2 & 5.5 & 3.6 & 8.9 & 10.5 & 5.8 \\
\hline 0 & 1 & 1.5 & 2.1 & 2.4 & 2.4 & 1.7 & 2.9 & 3.7 & 1.7 \\
\hline 0 & 1.5 & 1.5 & 1.6 & 1.6 & 1.7 & 1.4 & 2.4 & 2.7 & 1.8 \\
\hline 0.5 & 0.5 & 0.5 & 16.2 & 24.9 & 57.8 & 69.7 & 55.9 & 52.4 & 55.9 \\
\hline 0.5 & 0.5 & 0.75 & 9.6 & 14.6 & 33.0 & 35.7 & 34.0 & 29.5 & 35.7 \\
\hline 0.5 & 0.5 & 1 & 5.3 & 8.3 & 15.7 & 13.8 & 14.4 & 13.1 & 11.9 \\
\hline 0.5 & 0.5 & 1.5 & 2.4 & 3.1 & 3.9 & 2.8 & 3.0 & 3.1 & 2.4 \\
\hline 0.5 & 0.75 & 0.75 & 6.9 & 9.5 & 23.5 & 26.4 & 26.2 & 24.6 & 27.4 \\
\hline 0.5 & 0.75 & 1 & 4.5 & 6.0 & 13.3 & 13.1 & 15.2 & 14.2 & 13.9 \\
\hline 0.5 & 0.75 & 1.5 & 2.3 & 2.6 & 3.9 & 3.0 & 3.6 & 3.7 & 2.5 \\
\hline 0.5 & 1 & 1 & 3.4 & 4.2 & 9.1 & 8.9 & 11.6 & 11.2 & 11.4 \\
\hline 0.5 & 1 & 1.5 & 2.0 & 2.2 & 3.5 & 2.9 & 3.9 & 4.1 & 2.8 \\
\hline 0.5 & 1.5 & 1.5 & 1.6 & 1.5 & 2.3 & 1.9 & 3.0 & 3.1 & 2.7 \\
\hline 0.75 & 0.75 & 0.75 & 5.5 & 6.7 & 19.3 & 24.9 & 18.4 & 16.9 & 18.3 \\
\hline 0.75 & 0.75 & 1 & 3.9 & 4.6 & 12.3 & 14.7 & 12.9 & 10.9 & 14.5 \\
\hline 0.75 & 0.75 & 1.5 & 2.2 & 2.3 & 4.1 & 3.6 & 3.7 & 3.4 & 3.1 \\
\hline 0.75 & 1 & 1 & 3.0 & 3.4 & 9.2 & 11.2 & 9.9 & 9.1 & 10.5 \\
\hline 0.75 & 1 & 1.5 & 1.9 & 1.9 & 3.8 & 3.6 & 4.0 & 3.7 & 3.6 \\
\hline 0.75 & 1.5 & 1.5 & 1.5 & 1.5 & 2.5 & 2.4 & 3.1 & 3.0 & 3.0 \\
\hline 1 & 1 & 1 & 2.5 & 2.7 & 7.6 & 10.1 & 7.2 & 6.6 & 7.2 \\
\hline 1 & 1 & 1.5 & 1.8 & 1.8 & 3.6 & 4.0 & 3.7 & 3.2 & 4.0 \\
\hline 1 & 1.5 & 1.5 & 1.4 & 1.4 & 2.5 & 2.9 & 2.8 & 2.7 & 3.0 \\
\hline 1.5 & 1.5 & 1.5 & 1.2 & 1.2 & 2.1 & 2.7 & 2.0 & 1.9 & 2.0 \\
\hline
\end{tabular}

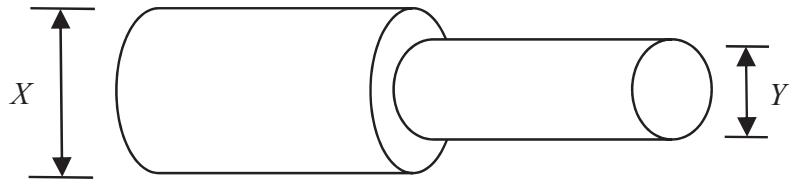

Fig. 2. A solid circular bar.

does not affect the performance of the ACS chart. The idea was also extended to monitor the trivariate mean vectors. This feature is an advantage of the ACS mp chart, once the design of the competing Max D and $T^{2}$ charts requires an accurate estimation of the $X$ and $Y$ correlation. Moreover, the ACS $m p$ chart outperforms the Max D chart, even with fewer observations per sample.

The ACS $m p$ chart is operationally simpler than the competing Max $D$ and $T^{2}$ charts thanks to the fact that this chart works with only one quality characteristic per time. Additionally, dealing with only one quality characteristic per time also reduces the risk of misclassifications and the risk of miscalculations during the determination of the sample points. In summary, the ACS chart is an excellent chart to control bivariate and trivariate mean vectors.

When nonconforming items are rarely produced, Zhang, Xie, and Jin (2012) suggested the monitoring of the cumulative number of conforming samples (CCC) until a non-conforming one is encountered. A nonconforming sample is the one with at least one nonconforming item. Recent studies dealing with the control of high-quality processes include the work of Lee and Khoo (2015); Ali, Pievatolo and Göb (2016); Joekes, Smrekar and Righetti (2016); Morais (2017) and Golbafian, Fallahnezhad and Zare Mehrjerdi (2017). The CCC chart with alternated charting statistic seems to be an interesting way to control high-quality bivariate (or trivariate) processes. The strategy of alternating the charting statistic increases the complexity of the CCC distribution, in special with the presence of the assignable cause. 


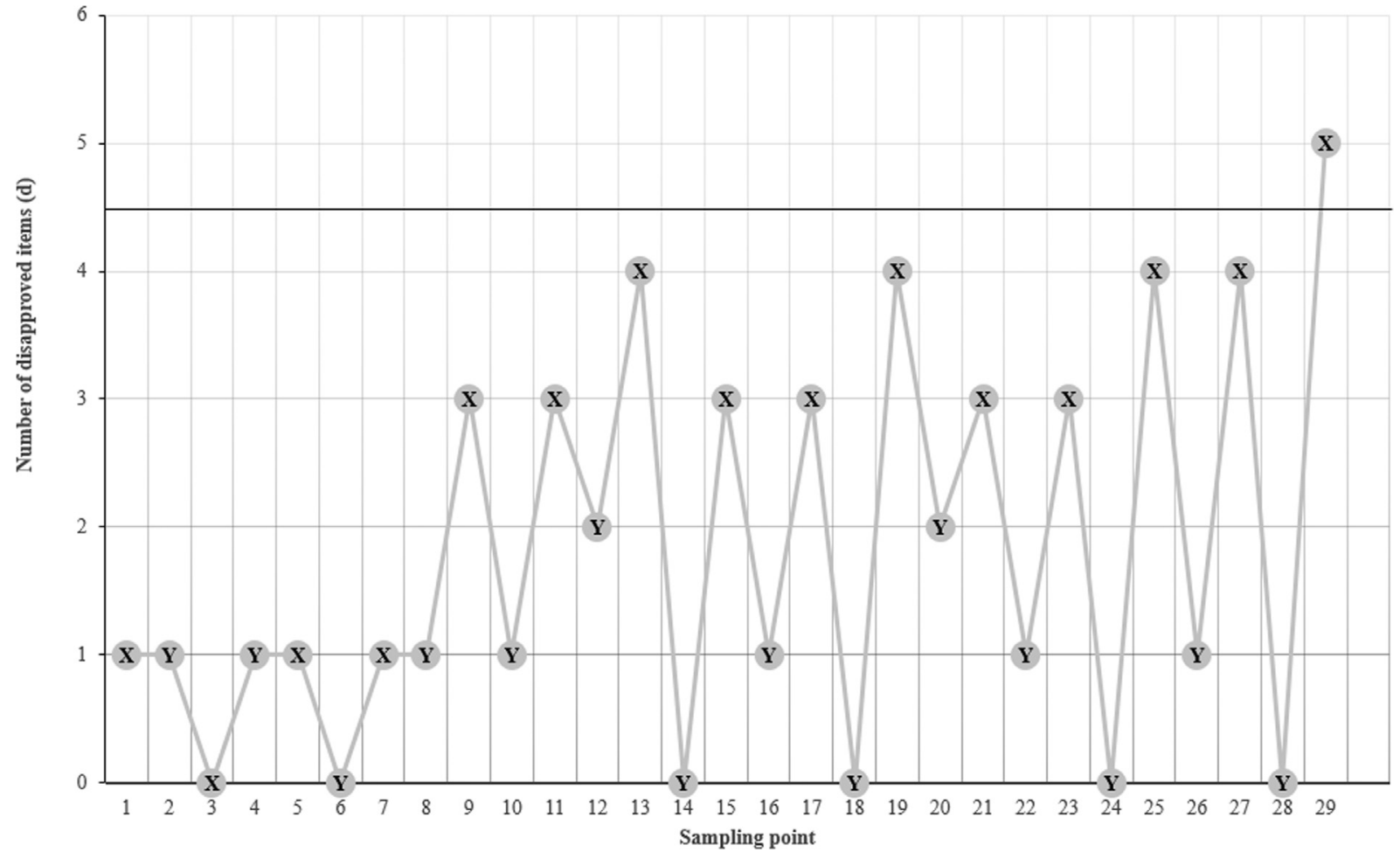

Fig. 3. The ACS $m p$ chart of the illustrative example.

Table 7

The ACS mp chart of the illustrative example with a step number column.

\begin{tabular}{|c|c|c|c|c|c|c|c|c|c|c|}
\hline $\begin{array}{l}\text { Sampling } \\
\text { point }\end{array}$ & $(X, Y)$ & Step & \multicolumn{7}{|c|}{ Sample items } & $\begin{array}{l}\text { Number of } \\
\text { disapproved items }(d)\end{array}$ \\
\hline 1 & $X$ & 5 & $0^{\mathrm{a}}$ & 0 & 1 & 0 & 0 & 0 & 0 & 1 \\
\hline 3 & $x$ & 5 & 0 & 0 & 0 & 0 & 0 & 0 & 0 & 0 \\
\hline 4 & $Y$ & 6 & 0 & 0 & 0 & 1 & 0 & 0 & 0 & 1 \\
\hline 5 & $X$ & 5 & 0 & 1 & 0 & 0 & 0 & 0 & 0 & 1 \\
\hline 6 & $Y$ & 6 & 0 & 0 & 0 & 0 & 0 & 0 & 0 & 0 \\
\hline 9 & $x$ & 5 & 0 & 0 & 1 & 0 & 1 & 1 & 0 & 3 \\
\hline 10 & $Y$ & 6 & 0 & 0 & 0 & 0 & 1 & 0 & 0 & 1 \\
\hline 11 & $X$ & 5 & 0 & 1 & 1 & 1 & 0 & 0 & 0 & 3 \\
\hline 12 & $Y$ & 6 & 1 & 0 & 0 & 1 & 0 & 0 & 0 & 2 \\
\hline 13 & $x$ & 5 & 1 & 1 & 1 & 1 & 0 & 0 & 0 & 4 \\
\hline 14 & $Y$ & 6 & 0 & 0 & 0 & 0 & 0 & 0 & 0 & 0 \\
\hline 15 & $x$ & 5 & 0 & 0 & 0 & 1 & 1 & 0 & 1 & 3 \\
\hline 21 & $x$ & 5 & 0 & 1 & 1 & 1 & 0 & 0 & 0 & 3 \\
\hline 22 & $Y$ & 6 & 1 & 0 & 0 & 0 & 0 & 0 & 0 & 1 \\
\hline 23 & $X$ & 5 & 1 & 1 & 0 & 1 & 0 & 0 & 0 & 3 \\
\hline 24 & $Y$ & 6 & 0 & 0 & 0 & 0 & 0 & 0 & 0 & 0 \\
\hline 25 & $x$ & 5 & 0 & 1 & 0 & 1 & 1 & 1 & 0 & 4 \\
\hline 26 & $Y$ & 6 & 1 & 0 & 0 & 0 & 0 & 0 & 0 & 1 \\
\hline 27 & $X$ & 5 & 1 & 1 & 1 & 0 & 0 & 1 & 0 & 4 \\
\hline 28 & $Y$ & 6 & 0 & 0 & 0 & 0 & 0 & 0 & 0 & 0 \\
\hline 29 & $X$ & 7 & 1 & 1 & 1 & 0 & 1 & 1 & 0 & 5 \\
\hline
\end{tabular}

${ }^{\mathrm{a}} 0$ (1) means an approved (disapproved) item. 


\section{Acknowledgments}

The authors are thankful to the reviewers and the editor for the useful comments to improve the initial version of the article. This work was supported by CNPq-National Council for Scientific and Technological Development (grant no. 304599/2015-8 and 402559/ 2016-9)

\section{Appendix A. The ARL of the ACS $m p$ chart}

The ARL of the ACS $m p$ chart depends on the charting statistic in use just after the assignable cause occurrence. The charting statistic is the number of disapproved sample items according to the $X(Y)$ discriminate limits. If the charting statistic in use, just after the assignable cause occurrence, is the number of disapproved sample items with regard to the $X$ dimension $\left(d_{\mathrm{x}}\right)$, then its power of signaling with the first sample is $p_{X}$, with the second sample is $q_{X} p_{Y}$, with the third one is $q_{X} q_{Y} p_{X}$, etc. Reminding that $q_{X}=1-p_{X}$ and $q_{Y}=1-p_{Y}$. This way, when $d_{\mathrm{x}}$ is the charting statistic in use, just after the assignable cause occurrence, the $A R L$ expression, defined as $A R L_{X}$ is:

$A R L_{X}=\sum_{i=0}^{\infty}\left(q_{X} q_{Y}\right)^{i}\left[(2 i+1) p_{X}+2(i+1) q_{X} p_{Y}\right]=\frac{p_{X}\left(1+q_{X} q_{Y}\right)+2 p_{Y} q_{X}}{\left(1-q_{X} q_{Y}\right)^{2}}$

Proof of Eq. (A1).

The $A R L_{X}=\Sigma_{x}+\Sigma_{y}$, where $\Sigma_{x}\left(\Sigma_{y}\right)$ is the probability to obtain a signal with the monitoring statistic $d_{\mathrm{x}}\left(d_{\mathrm{y}}\right)$.

It follows that:

$\Sigma_{x}=p_{x} \sum_{i=1}^{\infty}(2 i-1) q_{x}^{i-1} q_{y}^{i-1}=\frac{2 p_{x}}{1-q_{x} q_{y}} \sum_{i=1}^{\infty} i q_{x}^{i-1} q_{y}^{i-1}\left(1-q_{x} q_{y}\right)-p_{x} \sum_{i=1}^{\infty} q_{x}^{i-1} q_{y}^{i-1}=\frac{2 p_{x}}{\left(1-q_{x} q_{y}\right)^{2}}-\frac{p_{x}}{1-q_{x} q_{y}}=\frac{p_{x}\left(1+q_{x} q_{y}\right)}{\left(1-q_{x} q_{y}\right)^{2}}$

$\Sigma_{y}=\sum_{i=1}^{\infty}\left(2 i q_{x} p_{y}\right) q_{x}^{i-1} q_{y}^{i-1}=\frac{2 q_{x} p_{y}}{1-q_{x} q_{y}} \sum_{i=1}^{\infty} i q_{x}^{i-1} q_{y}^{i-1}\left(1-q_{x} q_{y}\right)=\frac{2 p_{y} q_{x}}{\left(1-q_{x} q_{y}\right)^{2}}$

Similarly, when $d_{\mathrm{y}}$ is the charting statistic in use, just after the assignable cause occurrence, the $A R L$ expression, defined as $A R L_{Y}$ is:

$A R L_{Y}=\frac{p_{Y}\left(1+q_{X} q_{Y}\right)+2 p_{X} q_{Y}}{\left(1-q_{X} q_{Y}\right)^{2}}$

The $A R L$ of the bivariate ACS $m p$ chart is given by the average of the $\left(A R L_{X}, A R L_{Y}\right)$ :

$A R L=\frac{A R L_{X}+A R L_{Y}}{2}=\frac{4-\left(p_{X}+p_{Y}\right)}{2\left(p_{X}+p_{Y}-p_{X} p_{Y}\right)}$

Extending to the trivariate case:

$A R L_{a}(a, b, c)=\sum_{i=1}^{\infty} q^{i-1}\left[(3 i-2) p_{a}+(3 i-1)\left(1-p_{a}\right) p_{b}+3 i\left(1-p_{a}\right)\left(1-p_{b}\right) p_{c}\right]=\frac{3\left[p_{a}+\left(1-p_{a}\right) p_{b}+\left(1-p_{a}\right)\left(1-p_{b}\right) p_{c}\right]}{(1-q)^{2}}-\frac{2 p_{a}+\left(1-p_{a}\right) p_{b}}{1-q}$

Expression (A4), with $q=\left(1-p_{X}\right)\left(1-p_{Y}\right)\left(1-p_{Z}\right)$, is the general expression of the $A R L_{X}, A R L_{Y}$, and $A R L_{Z}$, that is, $A R L_{X}=A R L_{X}(X, Y, Z)$, $A R L_{Y}=A R L_{Y}(Y, Z, X)$ and $A R L_{Z}=A R L_{Z}(Z, X, Y)$. The $A R L$ of the trivariate $A C S m p$ chart is given by the average of the $\left(A R L_{X}, A R L_{Y}, A R L_{Z}\right)$ :

$A R L=\frac{A R L_{X}+A R L_{Y}+A R L_{Z}}{3}=\frac{9-3\left(p_{x}+p_{y}+p_{z}\right)+\left(p_{x} p_{y}+p_{x} p_{z}+p_{y} p_{z}\right)}{3\left(p_{x}+p_{y}+p_{z}-p_{x} p_{y}-p_{x} p_{z}-p_{y} p_{z}+p_{x} p_{y} p_{z}\right)}$

\section{References}

Ali, S., Pievatolo, A., \& Göb, R. (2016). An overview of control charts for high-quality processes. Quality and Reliability Engineering International, 32(7), 2171-2189. http:// dx.doi.org/10.1002/qre.1957.

Aparisi, F., Epprecht, E. K., \& Mosquera, J. (2018). Statistical process control based on optimum gages. Quality and Reliability Engineering International, 34(1), 2-14. http:// dx.doi.org/10.1002/qre.2135.

Aparisi, F., \& Lee Ho, L. (2018). M-ATTRIVAR: An attribute-variable chart to monitor multivariate process means. Quality and Reliability Engineering International, 34(2), 214-228. http://dx.doi.org/10.1002/qre.2250.

Aslam, M., Azam, M., Khan, N., \& Jun, C.-H. (2015). A mixed control chart to monitor the process. International Journal of Production Research, 53(15), 4684-4693. http://dx. doi.org/10.1080/00207543.2015.1031354.

Aslam, M., Khan, N., Aldosari, M. S., \& Jun, C.-H. (2016). Mixed control charts using EWMA statistics. IEEE Access, 4(c), 8286-8293. http://dx.doi.org/10.1109/ACCESS. 2016.2628915 .

Bezerra, E. L., Ho, L. L., \& Quinino, R. da C. (2018). GS2: An optimized attribute control chart to monitor process variability. International Journal of Production Economics, 195, 287-295. http://dx.doi.org/10.1016/j.ijpe.2017.10.023.

Golbafian, V., Fallahnezhad, M. S., \& Zare Mehrjerdi, Y. (2017). A new economic scheme for CCC charts with run rules based on average number of inspected items. Communications in Statistics - Theory and Methods, 46(24), 12023-12044. http://dx. doi.org/10.1080/03610926.2017.1291967.

Haridy, S., Wu, Z., Lee, K. M., \& Rahim, M. A. (2014). An attribute chart for monitoring the process mean and variance. International Journal of Production Research, 52(11), 3366-3380. http://dx.doi.org/10.1080/00207543.2013.875234.
Ho, L. L., \& Aparisi, F. (2016). ATTRIVAR: Optimized control charts to monitor process mean with lower operational cost. International Journal of Production Economics, 182 472-483. http://dx.doi.org/10.1016/j.ijpe.2016.09.011.

Ho, L. L., \& Costa, A. F. B. (2011). Monitoramento da média de processos que oscila através de um gráfico de controle np. Production, 21(2), 254-258. http://dx.doi.org/ 10.1590/S0103-65132011005000027.

Ho, L. L., \& Costa, A. F. B. (2015). Attribute charts for monitoring the mean vector of bivariate processes. Quality and Reliability Engineering International, 31(4), 683-693. http://dx.doi.org/10.1002/qre.1628.

Ho, L. L., \& Quinino, R. C. (2013). An attribute control chart for monitoring the variability of a process. International Journal of Production Economics, 145(1), 263-267. http:// dx.doi.org/10.1016/j.ijpe.2013.04.046.

Ho, L. L., \& Quinino, R. da C. (2016). Combining attribute and variable data to monitor process variability: MIX S 2 control chart. The International Journal of Advanced Manufacturing Technology, 87(9-12), 3389-3396. http://dx.doi.org/10.1007/s00170016-8702-5.

Joekes, S., Smrekar, M., \& Righetti, A. F. (2016). A comparative study of two proposed CCC- $\mathrm{r}$ charts for high quality processes and their application to an injection molding process. Quality Engineering, 28(4), 467-475. http://dx.doi.org/10.1080/08982112. 2016.1172092.

Lee, M. H., \& Khoo, M. B. C. (2015). Variable sampling interval cumulative count of conforming chart with runs rules. Communications in Statistics - Simulation and Computation, 44(9), 2410-2430. http://dx.doi.org/10.1080/03610918.2013. 839035.

Leoni, R. C., \& Costa, A. F. B. (2017). Monitoring bivariate and trivariate mean vectors with a Shewhart chart. Quality and Reliability Engineering International, 1-8. http://dx. doi.org/10.1002/qre.2165.

Machado, M. A. G., Ho, L. L., \& Costa, A. F. B. (2018). Attribute control charts for 
monitoring the covariance matrix of bivariate processes. Quality and Reliability Engineering International, 34(2), 257-264. http://dx.doi.org/10.1002/qre.2253.

Melo, M. S., Ho, L. L., \& Medeiros, P. G. (2017b). Max D: An attribute control chart to monitor a bivariate process mean. International Journal of Advanced Manufacturing Technology, 90(1-4), 489-498. http://dx.doi.org/10.1007/s00170-016-9368-8.

Melo, M. S., Ho, L. L., \& Medeiros, P. G. (2017a). A 2-stage attribute-variable control chart to monitor a vector of process means. Quality and Reliability Engineering International, 33(7), 1589-1599. http://dx.doi.org/10.1002/qre.2127.

Morais, M. C. (2017). ARL-unbiased geometric and CCC G control charts. Sequential Analysis, 36(4), 513-527. http://dx.doi.org/10.1080/07474946.2017.1394717.

Quinino, R. C., Bessegato, L. F., \& Cruz, F. R. B. (2017). An attribute inspection control chart for process mean monitoring. The International Journal of Advanced Manufacturing Technology, 90(9-12), 2991-2999. http://dx.doi.org/10.1007/s00170016-9627-8.

Quinino, R. da C., Ho, L. L., \& Trindade, A. L. G. (2015). Monitoring the process mean based on attribute inspection when a small sample is available. Journal of the
Operational Research Society, 66(11), 1860-1867. http://dx.doi.org/10.1057/jors. 2014.102.

Sampaio, E. S., Ho, L. L., \& de Medeiros, P. G. (2014). A combined npx-X_bar control chart to monitor the process mean in a two-stage sampling. Quality and Reliability Engineering International, 30(7), 1003-1013. http://dx.doi.org/10.1002/qre.1528.

Wu, Z., \& Jiao, J. (2008). A control chart for monitoring process mean based on attribute inspection. International Journal of Production Research, 46(15), 4331-4347. http:// dx.doi.org/10.1080/00207540601126770.

Wu, Z., Khoo, M. B. C. C., Shu, L., \& Jiang, W. (2009). An np control chart for monitoring the mean of a variable based on an attribute inspection. International Journal of Production Economics, 121(1), 141-147. http://dx.doi.org/10.1016/j.ijpe.2009.04. 021.

Zhang, C. W., Xie, M., \& Jin, T. (2012). An improved self-starting cumulative count of conforming chart for monitoring high-quality processes under group inspection. International Journal of Production Research, 50(23), 7026-7043. http://dx.doi.org/ 10.1080/00207543.2011.649305. 